\title{
Variations in bacterial pathogens causing early onset neonatal septicaemia, according to birth weights - a 5 year study in a referral hospital of West- Bengal
}

\author{
Tapan Kumar Chattopadhyay ${ }^{1}$, Hirak Jyoti Raj ${ }^{2}$ \\ ${ }^{1}$ Department of Microbiology, Burdwan medical College, ${ }^{2}$ Burdwan;Department of Microbiology, Burdwan \\ Medical College, Burdwan.
}

\begin{abstract}
Bacterial sepsis continues to be a major cause of morbidity and mortality in neonates. The features of sepsis being non- specific, a high index of suspicion can only save a precious life. Pathogens of early onset septicaemia may vary, from one country to another and within a country from one place to the other. This study had been undertaken $t o$ understand the variations in the pathogens of early onset neonatal septicaemia according to birth weights ,their susceptibility patterns to commonly used antibiotics in this age of emerging resistance and to utilise this data for better empirical treatment of this potentially fatal conditions. Blood samples from 255 babies belonging to various birth weights and of both sexes with definitive inclusion and exclusion criteria were processeed according to standard laboratory protocols during a five year period, from February 2005-2010, in a rural referral hospital of West Bengal. Culture positivity was found in $63 / 255$ samples $(24.70 \%)$, comprising of Klebsiella pneumoniae (31.74\%) and methicillin sensitive Staphylococcus aureus (31.74\%) as predominant isolates. Male: female ratio was 1.25:1. The susceptibility pattern of isolates has been discussed. It is observed that bacteriology of early onset neonatal septicaemia varies according to birth weights. In very low birth weight babies Eshcherichia coli is the predominant organism and culture positivity is highest $(\mathbf{8 7 . 5 \% )})$. Where as culture postivity in low birth weight and normal weight babies with sepsis are $\mathbf{3 2 . 8 9 \%}$ and $\mathbf{2 9 . 2 6 \%}$ respectively.In low birth weight babies Staphylococcus aureus and in normal weight babies Klebsiella pneumoniae are the predominant organisms. Birth weight of babies and development of neonatal sepsis are significantly associated $x^{2}=7.174, p<0.03$. Male babies are more susceptible to develop neonatal sepsis.For initial therapy of early onset neonatal septicemia, Amikacin is the best choice.
\end{abstract}

Key words: Blood culture isolates. Early onset neonatal septicaemia. Low birth weight, drug resistance.

\section{Introduction}

Sepsis is the major killer of neonates in our country and the rates of neonatal sepsis are 10-20 times that of developed countries .The incidence of sepsis according to the data from National neonatal perinatal database (NNPD, 2002-2003) is

\section{Correspondence:}

Dr Tapan Kumar Chattopadhyay

Associate Professor

Department of Microbiology, Burdwan medical College

Indraprastha, Baburbag, Burdwan, 713104

Mobile 98321-73956

E mail: drtapanmicroprof@gmail.com
30/1000 live births ${ }^{(1)}$. Definition wise, Neonatal sepsis is the systemic bacterial infection of neonates.It is essentially a broad term, incorporating septicaemia, pneumonia, and meningitis of the newborn ${ }^{(2)}$. Neonatal sepsis can also be classified according to the age of onset of the disease. Early onset sepsis (EOS) presents within 72 hours after birth and late onset sepsis (LOS) presents after 72 hours. (2). Organisms infecting a newborn, resulting in a systemic disease can be acquired intranatally or postnatally. Type of organism varies with the mode and time of acquiring infection and also on the condition of the host. It is seen that gram negative organisms like Klebsiella spp, Escherichia coli 
are usual causes of EOS; while Staphylococcus aureus from NICU outbreaks or coagulase negative Staphylococcus aureus (CoNS) from intravenous cannulas and from other instruments are the causes of LOS.

Several organisms have been implicated for early onset neonatal septicaemia through out the globe, which may have geographical variations. These variations in the bacteriology of neonatal septicaemia have been observed in various time frames, and changes have also been seen in different countries and within the country from one palce to other. Ongoing suveillance for the past three quarters has documented shifts in the aetiological agents causing neonatal sepsis ${ }^{(3,4)}$. For the past thirty years group B Streptococcus has remained the most frequent pathogen causing early onset sepsis. E. coli has been the second most prevalent organism.A multicentre based report of very low birth weight neonates (401-1500 grams) admitted to 12 national institute of child health and human development (NICHD) neonatal research network centers during 32 month period from 1991-1993 noted, E. coli to be dominant early onset pathogen ${ }^{(5,6)}$.Not only there is a change in bacteriological profile but the isolated organisms may have regionwise changes in the susceptibilty patterns also. As far India is concerned, it is seen that GBS infection is not as endemic in our Indian NICUs as they were in the western world. A survey conducted by NNPD has observed the following results of 909 isolates -Klebsiella spp.31.2\%, Staphylococcus aureus 17.2\%, E. coli $10.5 \%$, Candida spp. $8.7 \%{ }^{(1)}$. When the above data is compared with the data obtained from 1995, NNPD, it is seen that there has been a rise in Klebsiella, S. aureus, Candida spp. and decrease in $E$. coli ${ }^{(7)}$ frequency.

Low birth weight (LBW), an indicator associated with the social status of women, has profound implications for neonatal health and survival and is an underlying factor in $40-80 \%$ or more of neonatal deaths ${ }^{(8,9)}$. This is of particular importance in South-East Asia where LBW rates are the highest, reaching nearly one-third. Several risk factors of mothers and neonates have been identifed which make the neonates susceptible to blood stream infections.Clinical features of sepsis are non specific in neonates and require a high index of suspicion for timely diagnosis.Sepsis related mortality is largely preventable with rational antimicrobial therapy and aggressive supportive care. It requires regular bacteriological monitoring in neonatal wards. The present study was done during February 2005 to February 2010 to look for the variable spectrum of bacteriological culture isolates and their antibiogram according to body weights of newborns in this region to facilitate better empirical treatment of septicaemic neonates.

\section{Methods}

Study design: In this study during 5 years, a total of 255 blood samples from different birth weight babies having various maternal factors namely a)Mothers having premature rupture of membrane $>24$ hours b)Mothers having foul smelling discharge per vagina c ) Mothers having meconium stained liquor d)Mothers having bad obstetrics history e)Febrile mothers f)Mothers having prolonged labour $\left(1^{\text {st }}\right.$ stage $+2^{\text {nd }}$ stage $>24$ hours $)$ g)Mothers having pregnancy induced hypertension were processed. Out of which 174 had positive symptoms of septicaemia/ bacterimia (poor feeding, respiratory distress, fever, irregular respiration).So these 174 babies were cases and their healthy counterparts being controls.

Inclusion criteria The babies who were born by normal vaginal delivery, normal delivery with

episiotomy or forceps, from mothers who had various risk factors like chorioamnionitis, prolonged rupture of membranes, and fever .

Exclusion criteria: Babies having congenital anomalies were excluded.

Standard procedure for blood collection was followed, and blood was cultured in conventional method poured in blood $(10,11)$. Culture bottles were maintained for 7 days before giving any negative report. The colonies were further identified by Gram staining and biochemical tests and were further confirmed by latex antigen detection test wherever applicable. [Wellcogen Bacterial Antigen Kit Streptococcus Gr B, Neisseria meningitidis A, B, C, Y, W135; Haemophilus influenzae type b, Streptococcus pneumoniae, and E.coli K1 antigen]. Antibiotic sensitivity test was done according to the NCCLS guidelines by Kirby -Bauer Disc diffusion method (12) .For the Enterococcus isolate Vancomycin Agar Screen was used.

\section{RESULTS}

Among 260 neonates, there were 63 positive cases (table 1). From 5 neonates blood could not be taken so there were altogether 255 cases. Out of clinically suspected 174 cases 97 are from males and 77 are from females. In very low birth weight babies $(<1.5 \mathrm{~kg})$ we have 9 males and 7 females, $14(87.5 \%)$ samples show growth, E. coli being the predominat organism. In low birth weight infants (1.5-2.49 grams), 111 in number, out of 76 suspected septicaemica cases 40 males and 36 females are there, 25(32.89\%) show culture postivity.In this group Staphylococcus aureus is the predominant organism and in normal weight infants $(2.5$ grams or above) 132 in number, out of 82 suspected case we have 48 males and 34 females, 24(29.26\%) show culture positivity. Klebsiella pneumoniae is the predominant organism. 
Table1. Shows the incidence of clinical sepsis/culture positive sepsis of babies belonging to different sexes and weights alongwith blood culture isolates.

\begin{tabular}{|c|c|c|c|c|c|c|c|c|}
\hline \multirow[t]{2}{*}{ Group } & \multicolumn{3}{|c|}{$\begin{array}{l}\text { Culture Babies } \\
\text { positive with }\end{array}$} & \multicolumn{5}{|c|}{ Organisms } \\
\hline & & $\begin{array}{l}\text { Clinical } \\
\text { sepsis }\end{array}$ & Klebsiella & Staph aureus & Enterobacter & Enterococcus & Pseudomonas & E. coli \\
\hline VLBW & & & & & & & & \\
\hline$<1.5 \mathrm{~kg}$ & 14 & 16 & - & 5 & - & - & 1 & 8 \\
\hline LBW & & & & & & & & \\
\hline 1.5 to $2.49 \mathrm{~kg}$ & 25 & 76 & 9 & 13 & 1 & - & - & 2 \\
\hline NORMAL & & & & & & & & \\
\hline $2.5 \mathrm{~kg}$ & 24 & 82 & 11 & 2 CONS-8 & 1 & 1 & - & 1 \\
\hline Total & 63 & 174 & 20 & 20, CONS-8 & 2 & 2 & 1 & 11 \\
\hline
\end{tabular}

VLBW < 1.5kg; LBW 1.5-2.49 Kg; NORMAL-Equal to/ > 2.5Kg; MALE: FEMALE RATIO 1.25:1

\section{ANTIMICROBIAL SUSCEPTIBILITY TEST:}

Susceptibility pattern of all blood culture isolates were done and shown in Table 2. Most of the

organisms found resistant to Ampicillin, Amoxyclav, Cephalexin and Cefixime, whereas the majority of the organisms were sensitive to Gattifloxacin and Vancomycin.

Table 2 Table showing micro-organisms and their resistance patterns towards different antimicrobials

\begin{tabular}{|c|c|c|c|c|c|c|c|}
\hline \multirow{3}{*}{ Antimicrobials } & \multirow{3}{*}{$\begin{array}{l}\text { Klebsiella } \\
\text { pneumoniae }\end{array}$} & \multirow{3}{*}{ S.aureus } & \multicolumn{3}{|c|}{ Organism } & \multirow{3}{*}{$\begin{array}{l}\text { Entero } \\
\quad \text { coccus } \\
\text { spp } \\
(\mathrm{N}=1)\end{array}$} & \multirow{3}{*}{$\begin{array}{l}\text { Pseudo } \\
\text { monas } \\
\text { spp } \\
(\mathrm{N}=1)\end{array}$} \\
\hline & & & E.coli & CoNS & $\begin{array}{l}\text { Entero } \\
\text { bacter }\end{array}$ & & \\
\hline & & & $(\mathrm{N}=11)$ & $(\mathrm{N}=8)$ & $\begin{array}{l}\mathrm{spp} \\
(\mathrm{N}=2)\end{array}$ & & \\
\hline Ampicillin & $20(100 \%)$ & $20(100 \%)$ & $11(100 \%)$ & $6(75 \%)$ & $2(100 \%)$ & $1(100 \%)$ & $1(100 \%)$ \\
\hline Cloxacillin & - & $10(50 \%)$ & $6(50 \%)$ & $4(50 \%)$ & - & - & - \\
\hline Amoxycillin & $18(90 \%)$ & $10(50 \%)$ & $11(100 \%)$ & $4(50 \%)$ & $2(100 \%)$ & $1(100 \%)$ & $1(100 \%)$ \\
\hline \multicolumn{8}{|c|}{ and clauvanalic acid } \\
\hline cephalexin & $14 \quad(70 \%)$ & $12(66.6 \%)$ & $7(63 \%)$ & $4(50 \%)$ & $2(100 \%)$ & $1(100 \%)$ & $1(100 \%)$ \\
\hline Cefixime & $10 \quad(50 \%)$ & $10(50 \%)$ & $4(36 \%)$ & $4(50 \%)$ & $2(100 \%)$ & $1(100 \%)$ & $1(100 \%)$ \\
\hline Ceftazidime & $8(40 \%)$ & $10(50 \%)$ & $4(36 \%)$ & $4(50 \%)$ & $2(100 \%)$ & $1(100 \%)$ & $0(0 \%)$ \\
\hline Gentamicin & $14(70 \%)$ & $7(33.33 \%)$ & $2(18 \%)$ & $4(50 \%)$ & $2(100 \%)$ & $1(100 \%)$ & $1(100 \%)$ \\
\hline Amikacin & $6(30 \%)$ & $6(33.33 \%)$ & $2(18 \%)$ & $0(0 \%)$ & $2(100 \%)$ & $1(100 \%)$ & 0 \\
\hline Chloramphencol & $10 \quad(50 \%)$ & $6(30 \%)$ & $4(36 \%)$ & $2(25 \%)$ & $2(100 \%)$ & $0(0 \%)$ & 0 \\
\hline Tetracycline & $14(70 \%)$ & $12(60 \%)$ & $8(72 \%)$ & $4(50 \%)$ & $2(100 \%)$ & $1(100 \%)$ & $1(100 \%)$ \\
\hline Erythromycin & - & $17(83.33 \%)$ & - & $6(75 \%)$ & - & $1(100 \%)$ & - \\
\hline Cotrimoxazole & $8(40 \%)$ & $6(30 . \%)$ & $4(36 \%)$ & $4(50 \%)$ & $2(100 \%)$ & $1(100 \%)$ & $1(100 \%)$ \\
\hline Clindamycin & - & $4(20 \%)$ & - & $2(25 \%)$ & - & - & - \\
\hline Cefuroxime & $6 \quad(30 \%)$ & $10(50 \%)$ & $6(54 \%)$ & $2(25 \%)$ & $2(100 \%)$ & $1(100 \%)$ & $1(100 \%)$ \\
\hline Gattifloxacin & $2(10 \%)$ & $6(30 \%)$ & $2(18 \%)$ & $2(25 \%)$ & $0(0 \%)$ & $0(0 \%)$ & $0(0 \%)$ \\
\hline Vancomycin & - & $3(16 \%)$ & - & $0(0 \%)$ & - & $0(0 \%)$ & - \\
\hline
\end{tabular}

\section{Discussion:}

In the present study blood culture positivity was $24.70 \%$ of the suspected septicaemic neonates. Since signs and symptoms of septicaemia overlap other disorders, diagnosis of septicaemia is a common problem. However the negative culture of such a huge proportion(75.29\%) may be due to administration of antibiotics before blood collection, or infection with a non culturable agent. Some reports from home and abroad shows the incidence of neonatal septicaemia to vary between $36-55 \%$.In this study the culture positivity was $24.70 \%$ and it was found in 63 out of 255 samples. $E$ .coli is the predominant organism in VLBW babies and culture positivity is highest in clinically suspected neonates $(87.5 \%)$. Where as culture postivity in low birth weight and normal weight babies with sepsis are $32.89 \%$ and $29.26 \%$ respectively.In low birth weight babies Staph. aureus and in normal weight babies Klebsiella pneumoniae are the predominant organisms. Similar finding were reported from other studies conducted in different parts of India.

The predominance of gram negative organisms is different from what has been seen in other parts of globe where Group B Streptococcus has been implicated to be commonest one. (13-15) Out of 63 positive isolates, most of the organisms found resistant to ampicillin, amoxyclav, cephalexin and cefoxitin, whereas these organisms shows higher rate of sensitivity to gattifloxacin and vancomycin. Khaneja et al ${ }^{(17)}$ found (1999) quinolones to be effetive in the treatment of multidrug resistant. Gram negative infections in patients including extremely low birth weight infants. But because of the associated toxicity it is better to be left in the hands of neonatologists to think for fluoroquinolones. Looking at the above resistance pattern the most effective drug appears to be amikacin and it appears to be the best choice, against which although, resistance patterns are slowly evolving.

The limitation of our study was the positive history of antibiotics administered just after resuscitation of the baby and some cases were not recognised at all to be suffering from septicemias because of the subtle manifestations. The key massage of this study is regular region wise surveillance for bacteriological aetiology of neonatal septicemia should be part and parcel of every hospital infection control programme. Appropriate application of this knowledge is the answer for early onset neonatal septicemia because it is largely preventable if there is high index of suspicion and timely action at the earliest, to fulfill the dreams of millions of mothers for a healthy child.

\section{REFERENCES:}

1. National Neonatal Perinatal Database. Report for the year 2002. India: National Neonatology Forum: 2002.

2. Neonatal Sepsis'. Paul V, Aggarwal R. Manual of Neonatal 
Care; Mondkar J, Pejaver RK (eds); National Neonatology Forum. Prism Books, Bangalore; 2004

3. Bizzano MJ, Raskind C, Bizzano MJ, Raskind C, Baltimore RS,et al. Seventy five years of neonatal sepsis at Yale: 19282003.Paediatrics 2005:116:595-602

4. Stoll BJ. Infection of the Neonatal Infant. In Nelson's Text Book of Paediatrics; Behrman RE, Kleigman RM, Jenson HB. $18^{\text {th }}$ eds;WB Saunders Co.2006,794-811

5. Stoll BJ,Hansen N,Fanaroff A et al.Changes in pathogens causing early onset sepsis in very low birth weight infants. N Eng J Med 2002; 347:240-247

6. StollBJ, Hansen N, fanaroff, Lemons JA from national institute of chiold health and human development, Neonatal research network. Study done at Dept. of Pediatrics, Emary univ. School of Medicine, Atlanta; Research TriangleInstitute, North Carolina, Dept. of Pediatrics, Cave Western Reserve Univ., Cleveland, Ohio; Dept. of Pediatrics, Indiana Univ., Indianapolis, Indiana, USA.

7. Report of National Neonatal Perinatal Database, 1995. (National Neonatology Forum)

8. Zupan J, Perinatal mortality in developing countries .N Engl J Med 2005;352: 2047- 810.1058 /NEJMp058032; pmid: 10949213

9. Lawn JE, Cousen S, Jupan J, 4 million neonatal deaths: when? Where? Why Lancet 891- 900 doi: 10.10.1016/ S0140-6736 (05)71048-spmiod: 15752534.)

10. Gerdes JS.Diagnosis and management of bacterial infection in neonate.paediatr clinN Am2004; 51:939-959 Wilkins.

11. Baron EJ, Fine gold SM (EDS) Overview of conventional methods for bacterial identification Chapter 13, In: Bailey and Scotts's diagnostic Microbiology (Mosby publishers .S t Louis 1994:167

12. Performance Standards for antimicrobial susceptibility testing .Eigth information Supplement 2000.National committee for clinical laboratory Standards (NCCLS) M2A7 Vol 20, No.1 and 2 Villanova, Pa.

13. K.K Roy, Jinee Baruah, Suresh Kumar, Neena Malhotra, A.K. Deorari and J.B. Sharma, Maternal antenatal profile and immediate neonatal outcome in VLBW and ELBW babies, Indian Journal Paediatr. Vol 73(8): 669-673.

14. Basavaraj M. Kerur, B Vishnu Bhat, B.N. Harish, S. Habeebullah and C. Uday Kumar, Maternal genital bacteria and surface colonization in early neonatal sepsis. Indian j. Paediatr 2006, vol. 73:29-32

15. Shankar V, Paul VK, Singh M. Do neonates meconium aspiration syndromes require antibiotics. Indian J Pediatr
1995; 62: 327-331.

16. Das PK, Basu K Chakrabarty P, BhowmiK PK.clinical bacteriological profile of Neonatal infections in metropolitan city based medical college nursery .J ind Med assoc 1999;97:3-5.

17. Khaneja M .Neprawa J.kumar A.p Successful treament of late onset resistant Klebsiella pneumoniae in low birth weight infant using ciprofloxacin 1999:19:311-314. 